\title{
Study of real-time LWD data visual interpretation and geo-steering technology
}

\author{
Shao Cairui ${ }^{1 *}$, Zhang Fuming ${ }^{1}$, Chen Guoxing ${ }^{1}$, Ji Jiaqi ${ }^{2}$, Hou Qinggong ${ }^{3}$, \\ Tang Jianhong ${ }^{2}$ and Cao Xianjun ${ }^{1}$ \\ ${ }^{1}$ School of Geosciences, China University of Petroleum, Qingdao, Shandong 266580, China \\ ${ }^{2}$ CNPC West Drilling and Logging Company, Karamay, Xinjiang 834000, China \\ ${ }^{3}$ SINOPEC Shengli Well logging Company, Dongying, Shandong 257000, China
}

(C) China University of Petroleum (Beijing) and Springer-Verlag Berlin Heidelberg 2013

\begin{abstract}
LWD (logging while drilling) data has been used to explore complex subtle reservoirs by realtime visual interpretation and geo-steering. The method comprises of computer communication, well log data processing, formation recognition, reservoir modeling and model updating in real time. We studied the key technologies related to real-time LWD data visual interpretation and geo-steering and developed computer software with Chinese intellectual property rights covering the following important aspects: 1) real-time computer communication of well site LWD data;2) visualization of geological model and borehole information; 3) real-time interpretation of LWD data; 4) real-time geological model updating and geo-steering technology. We use field application examples to demonstrate the feasibility and validity of the proposed technologies.
\end{abstract}

Key words: LWD (logging while drilling), real-time, visualization, interpretation, geo-steering

\section{Introduction}

LWD (logging while drilling) technologies have been undergoing rapid development along with the wide use of high-angle well directional drilling technology to develop thin and subtle oil and gas reservoirs. LWD is used not only in formation evaluation when wireline logging is unavailable, but also for geo-steering into complex reservoirs to control the down-hole drill tool to hit the desired geological targets (Saikia, 2013; Swire et al, 2013; Liu et al, 2013).

LWD technology has made great progress in the last decade, LWD nuclear (Mickael et al, 2002; Wheeler et al, 2012) and electrical (Rosthal et al, 1995; Bazara et al, 2013 ) tools can now obtain measurement results that are comparable to those of wireline logging tools. Besides, the LWD response, being measured while drilling, is closer to the true formation value than the later wireline logging obtained after drilling. Great success has also been achieved in sonic LWD technologies (Tang et al, 2010) and NMR (Heaton et al, 2012). Schlumberger, Halliburton and Baker Hughes have made remarkable achievements in the LWD field. The Vision and Scope (www.slb.com/services/drilling/mwd lwd.aspx) series of Schlumberger LWD tools are examples of LWD technology evolution. For their LWD service, these companies also provide reservoir evaluation and geo-steering

*Corresponding author. email: shaocr@upc.edu.cn

Received June 20, 2013 software related to the tool hardware, together with drilling engineering control software, making their service more competitive (Shao et al, 2010).

The high service price and technological monopoly of those international companies limit the wide use of LWD technology, especially in low-budget situations. Therefore research into real-time LWD data visual interpretation and geo-steering technology with Chinese intellectual property rights is of great importance. For this purpose, the authors studied the key technology and developed corresponding software. Field application examples were used to demonstrate the feasibility and validity of the proposed software.

\section{Real-time reception of $L W D$ data at well site}

Real-time reception of LWD data in the field sets the foundation for the implementation of real-time interpretation and geo-steering.

\subsection{Standard format of WITS}

In general, domestic and international LWD ground control systems can provide a real-time data port for sending data to a third party, with a logical data recording structure. The international WITS (Well Information Transform Standard) format structure is widely utilized. The WITS format is consistent with the POSC (Petro-technical Open 
Software Corporation) standard. There are 25 standard record definitions (home.sprynet.com/ carob/) for all the drilling and measurement information at the well site. The 07 record is used for hole trajectory data (depth measurement, well deviation, and azimuth), and the 08 record is for the LWD data. WITS has both text and binary code formats. The record of text code starts with the punctuation mark " $\& \&$ " and ends by the punctuation mark "!!". Each line between " $\& \&$ " and "!!" contains one data item. Each data item includes three parts: data record identification, data item identification and data item value (Table 1).

Table 1 WITS data record example

\begin{tabular}{|c|c|c|c|c|}
\hline $\begin{array}{l}\text { Data record } \\
\text { line }\end{array}$ & $\begin{array}{c}\text { Record } \\
\text { mark }\end{array}$ & $\begin{array}{c}\text { Data item } \\
\text { mark }\end{array}$ & $\begin{array}{l}\text { Data item } \\
\text { value }\end{array}$ & Illustration \\
\hline$\& \&$ & & & & Start of record \\
\hline 0805090802 & 08 & 05 & 090802 & Date is August 2, 2009 \\
\hline 0806090336 & 08 & 06 & 090336 & Time is 9:3:36 a.m. \\
\hline 08087849.820 & 08 & 08 & 7849.82 & $\begin{array}{c}\text { Measure depth of borehole } \\
\text { is } 7849.82\end{array}$ \\
\hline 08095878.238 & 08 & 09 & 5878.238 & $\begin{array}{c}\text { True vertical depth } \\
\text { of borehole is } 5878.238\end{array}$ \\
\hline 08107852.650 & 08 & 10 & 7852.65 & $\begin{array}{l}\text { Measure depth of bit } \\
\text { is } 7852.65\end{array}$ \\
\hline 08115879.205 & 08 & 11 & 5879.205 & $\begin{array}{l}\text { True vertical depth of bit } \\
\text { is } 5879.205\end{array}$ \\
\hline 08217849.599 & 08 & 21 & 7849.599 & $\begin{array}{l}\text { Measure depth of gamma } \\
\text { is } 7849.599\end{array}$ \\
\hline 08225878.162 & 08 & 22 & 5878.162 & $\begin{array}{c}\text { True vertical depth } \\
\text { of gamma is } 5878.162\end{array}$ \\
\hline 082479.000 & 08 & 24 & 79 & The value of gamma is 79 \\
\hline !! & & & & End of record \\
\hline
\end{tabular}

\subsection{Real-time reception of WITS data with Socket network communication technology}

The interface of the Socket is an application programming interface (API) of a TCP/IP network. Programmers can use it to develop applications on TCP/IP network. The interface of the Socket was firstly realized in the UNIX operating system, and then transported to other operating systems including MS Windows (Jones and Ohlund, 2002). The point-to-point Winsock technology can complete the peer-to-peer computer data communications for wellsite upload. The wellsite WITS data generally uses the datagram socket transmission.

Using the above technology, the real-time borehole trajectory and logging data for each measurement depth can be obtained through receiving and decoding WITS data. The following is an example for the real-time GR logging data.

\footnotetext{
\#WITS Curve GR Attribute Items:

\# Dep Tvd HoleDep HoleTvd BitDep BitTvd Value Incl Azim

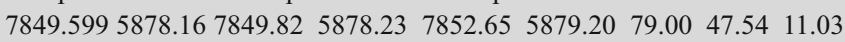

In order to implement geo-steering, the geological background model and wellbore data must be displayed in 3D in order to visualize the wellbore trajectory in the geological background. Many 3D visualization software development
}

kits can be used. The open graphics library, OpenGL (www. opengl.org; Li et al, 2002) provides a portable standard and open function package supporting different operating systems and GUIs (Graphical User Interfaces), which is an economic and simple 3D visualization SDK (Software Development Kit). In MS Windows, Visual $\mathrm{C}++$ is the first choice as the GUI development tool for OpenGL graphic applications.

\section{Geometry steering based on a pilot geological model and wellbore information visualization}

\subsection{D visualization of pilot geological model}

Pilot geological models can be obtained by formation correlation or geological modeling. Using Microsoft (www. microsoft.com) VC6.0 (Wang et al, 1999) and OpenGL, we have developed software that can display a geological model in 3D. Therefore, the geological structure configuration and formation boundaries can be effectively visualized from different angles of view.

For a 3D regular grid model, the node vertex is arranged in accordance with the horizontal and vertical directions. In a general way, lots of small cubes are drawn for the eight adjacent nodes. Then, many such cubes form a large scale geological structure. This method has high time and space complexity for large geological models (Lorensen and Cline, 1987). To reduce the complexity, we adopt a hollow display method which only displays the six external surfaces of the geological model as Fig. 1 (Levoy, 1988; Barillot, 1993). For displaying and analyzing the inner structure section slices are cut in different directions (Fig. 2). If the geological model is complex, we use irregular grid data to store and display it (Pears et al, 2012).

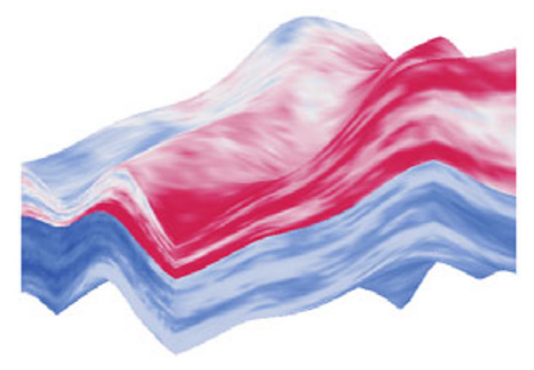

Fig. 1 Hollow display of geological model

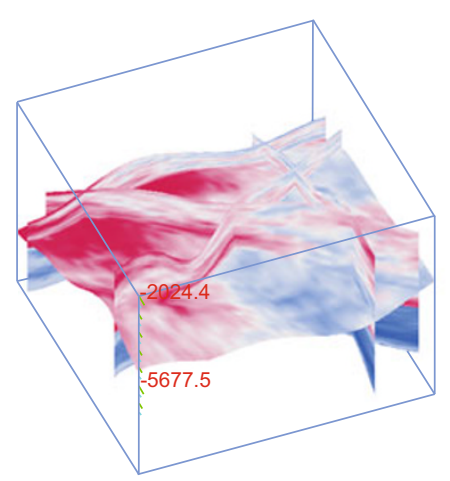

Fig. 2 Slices in different directions 


\subsection{Visualization of well trajectory \& borehole data information}

The minimum radius of curvature trajectory calculation method (Sawaryn and Thorogood, 2005) is utilized to calculate the three-dimensional coordinates of the drilling trajectory from the real-time measurement-while-drilling (MWD) data (depth, well deviation and deviation azimuth). Then the draw-line function of the OpenGL API is used to sequentially connect the $3 \mathrm{D}$ coordinate trajectory control points in $3 \mathrm{D}$ space. This way, a $3 \mathrm{D}$ borehole trajectory is displayed as Fig. 3.

3D visualization of a log curve is done by actually displaying the amplitude of 3D points $V(x, y, z)$ in 3D space, so it can be regarded as 4D data visualization. The drawing methods are as follows:

1) Get 3D coordinates of each logging point by interpolation with its measured depth and the 3D trajectory data.

2) Use the method of least squares to get the well trajectory plane equation, and then get the maximum inclined section plane of the trajectory.

3) Use the plane equation and 3D coordinates of each logging point, calculate the 3D coordinates with amplitude variation of each scaled log data value.

4) Connect each log data point according to their $3 \mathrm{D}$ coordinates, display the 3D well logging curve.

Note that the 3D log curve attributes (such as scale, color, width) can be adjusted to enhance the visual effect.

The scattered core data, segmented wellbore information such as log interpretation results (layer porosity, permeability, and fluid saturation) can also be displayed as 3D log curves or 3D column (see right of Fig. 3).
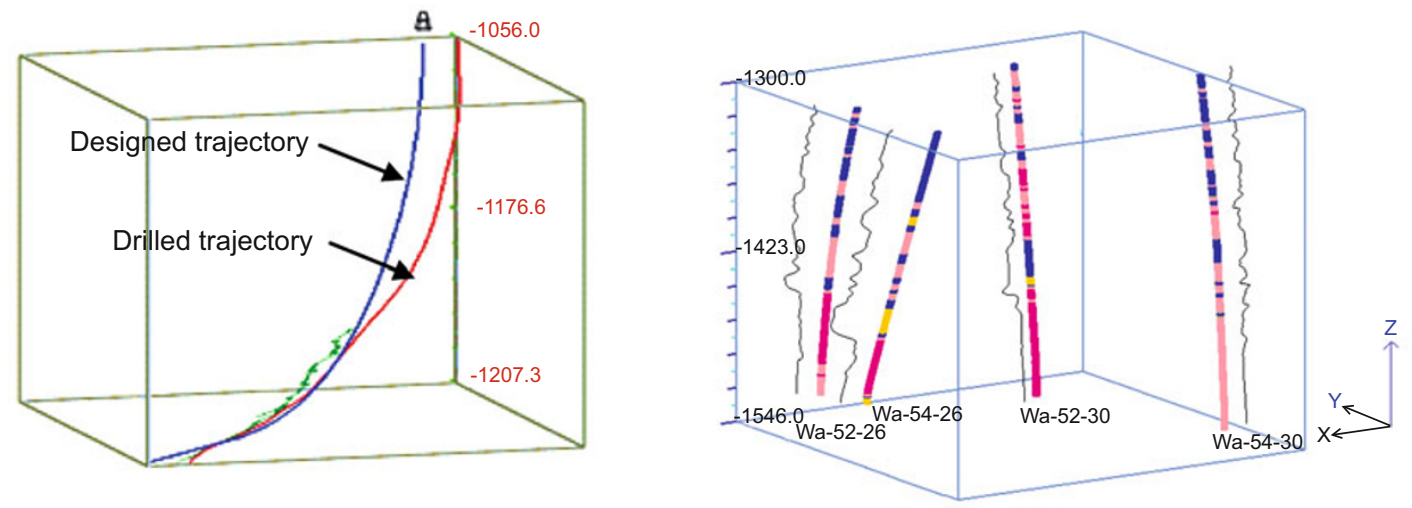

Fig. 3 Visualization of well trajectory and log data (different colors of column on right represent different rock types)

\subsection{Visual steering based on a pilot geological model $\&$ wellbore information}

\subsubsection{Geometry steering using wellbore trajectory and geological model in 3D}

Through the specified visualization method of point, line, surface, body and trajectory in 3D space, we implemented the visualization of the pilot geological model, well profiles of stratigraphic correlation, well trajectory, and wellbore data (core mark, log data and reservoir parameters) in a composite view background. Thereby we can visually describe the contact relationship of the well trajectory and geological body using the following functions:

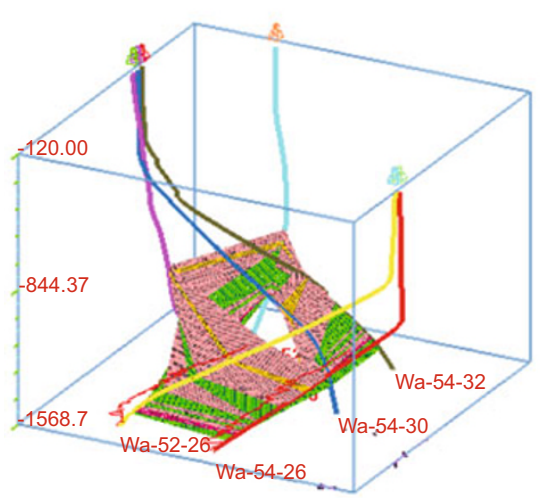

Contrast the difference between the designed trajectory and the drilled trajectory by the 3D well trajectory visualization.

Display the contact relationships between trajectory and formation by cutting the geological model and displaying the well profile along the well trajectory (Fig. 4 and Fig. 5).

Using rotation, zoom and pan to view the specified target, and to walk through the wellbore trajectory in the geological body from any angle.

Through analysis of contact relationship among designed trajectory, drilling trajectory, and pilot geological model using the above functions, we can implement geometric steering effectively.

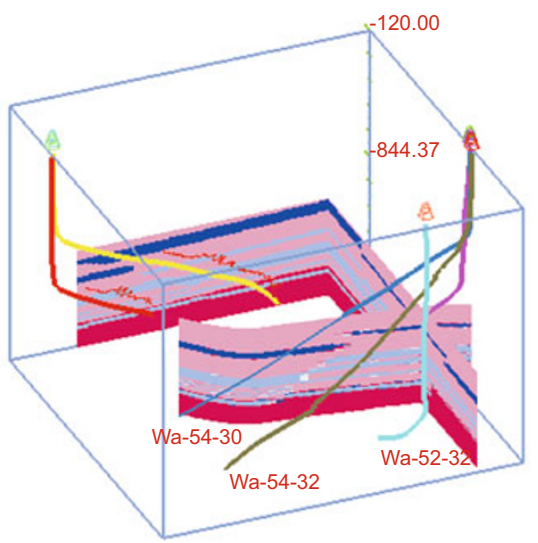

Fig. 4 Well trajectory display based on a stratigraphic correlation model (different color lines are different well trajectories, and the symbols on the top are the ground well sites) 


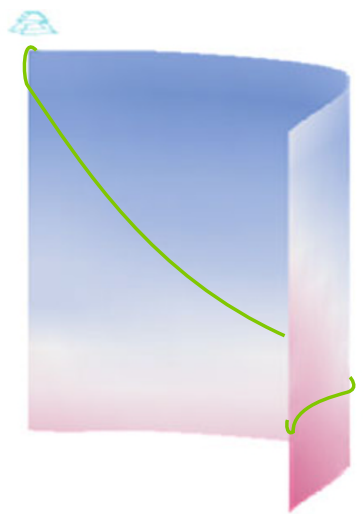

Fig. 5 Geological body cutting along the well trajectory

\subsubsection{Auxiliary steering with 2D projection relationship}

To view different trajectories (such as designed trajectory and drilling trajectory) and geological interfaces in a specified view angle, we provide top and side projection display of well

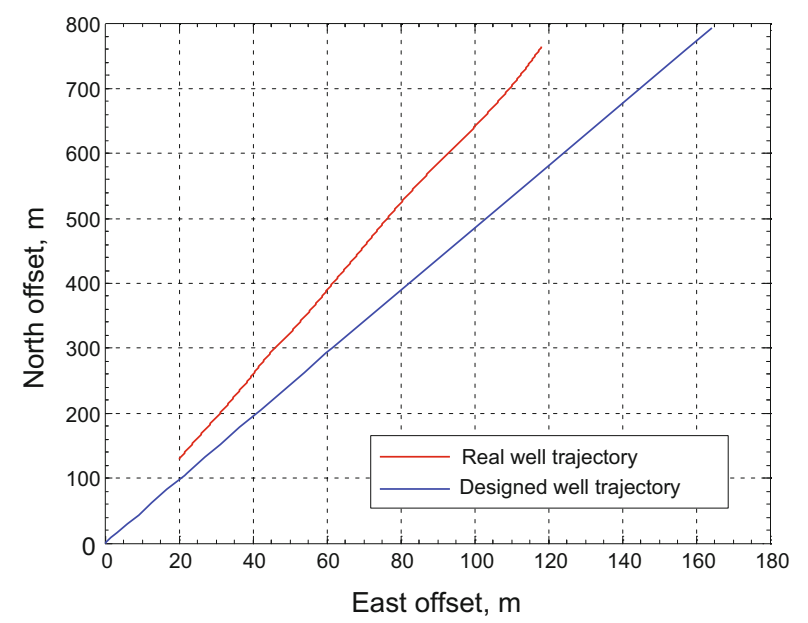

trajectory and pilot geological model (Fig. 6). This way, we can view the borehole trajectory horizontal deviation in the top projection display and the contact relationship between borehole trajectory and formation in the pilot strata model in a specified direction, so as to provide $2 \mathrm{D}$ geometric criteria for controlling the well trajectory.

\section{Real-time interpretation and geo-steering using LWD data}

Only with real-time interpretation of the LWD data, can the borehole trajectory and the reservoir information contained in the LWD data be displayed in real time. And only by this, can the formation interface, the lithology variation and the fluid information be interpreted in time. Also only by this, can we update geological model in real time, and adjust the drilling trajectory into the oil or gas layers. This way, an integrated technology for LWD interpretation and geo-steering can be realized.

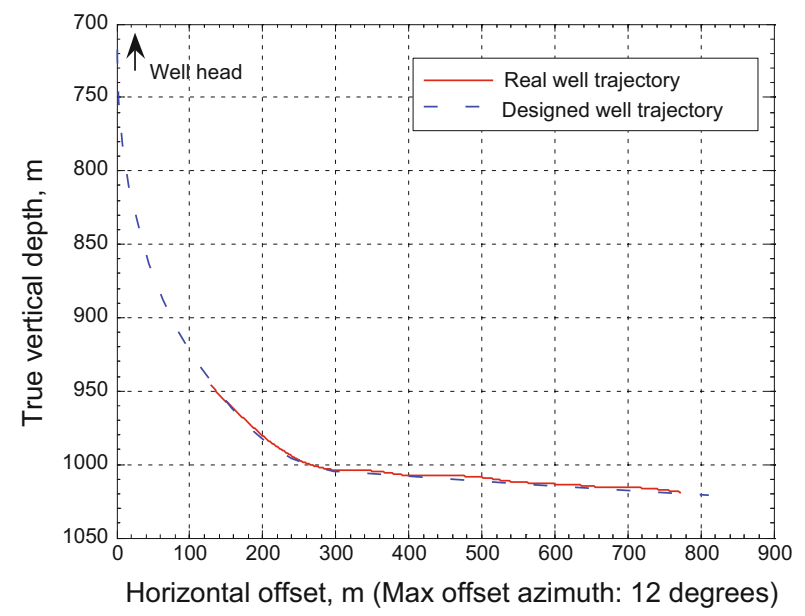

Fig. 62 projection display of well trajectory (Left: top view, right: side view)

\subsection{Visual real-time interpretation with LWD data}

\subsubsection{Pretreatment of LWD data}

The LWD data generally have low mud invasion, but are strongly influenced by the well deviation angle and surrounding layers (Liu et al, 2013). Therefore, before quantitatively calculating reservoir parameters, corrections for well inclination and the surrounding rocks should be made.

\subsubsection{Reservoir parameters interpretation models}

The reservoir parameters can be estimated using preprocessed LWD data. Guided by the wireline logging interpretation method, the shale content, parameters such as porosity, oil or water saturation, and permeability, can be estimated with the shale sands equivalent volume model. Appropriate models for the estimation can be used (Yong and Zhang, 1996; Schlumberger Wireline \& Testing, 1998). For the present domestic market, most LWD measurements only provide gamma-ray (GR) and resistivity log data. Only a few individual companies supply the compensated neuron $\log (\mathrm{CNL})$ and density log data. Therefore, the reservoir parameters are estimated using statistical models as follows:

\section{1) Shale content}

This parameter is estimated from the $G R$ curves using the conventional formula:

$$
S H=\frac{G R-G R_{\min }}{G R_{\max }-G R_{\min }}, V_{\mathrm{sh}}=\frac{2^{G C U R \times S H_{i}}-1}{2^{G C U R}-1}
$$

where $G R$ is log data; $G R_{\max }$ is the log data of pure shale formation; $G R_{\min }$ is the log data of a pure sand formation; GCUR is the region experience coefficient, which equals 3.7 in the Tertiary formation and 2.0 in the old formation. GCUR can be obtained from local data.

2) Porosity estimation with statistical shale content model

If there is no porosity log data (acoustic, density and neutron $\log$ ), the porosity can be estimated by the relationship between shale content and porosity. The statistics of experimental data show that there is a relationship between shale content and porosity. For example a regression model can be found below.

$$
P O R_{i}=A \times\left(1-S H_{i}\right)+B \times\left(1-S H_{i}\right)^{2}+C
$$

where $P O R_{i}$ is the porosity value at $i^{\text {th }}$ point; $S H_{i}$ is the relative 
amount of shale; $A, B$ and $C$ are the regression coefficients.

3) The matrix volume

With the estimation of the shale content and porosity, the matrix volume can be estimated by the volumetric model:

$$
V_{\mathrm{ma}}=1-P O R-V_{\mathrm{sh}}
$$

\section{4) Permeability}

When the rock physical property experimental data are available, the permeability can be calculated by the regression equation of porosity, shale content and permeability or through the Timur empirical formula (Timur, 1968; Balan et al, 1997).

\section{5) Formation water saturation}

(1) In shale sandstone formation, the Simandoux formula (Simandoux, 1963; Fertl and Hammack, 1972; Peeters, 2011) can be utilized to estimate the water saturation.

$$
S_{\mathrm{w}}=\frac{1}{\phi}\left\{\sqrt{\frac{0.81 R_{\mathrm{w}}}{R_{\mathrm{t}}}}-V_{\mathrm{sh}} \frac{R_{\mathrm{w}}}{0.4 R_{\mathrm{sh}}}\right\}
$$

where $R_{\mathrm{w}}$ is formation water resistivity, $R_{\mathrm{t}}$ is formation resistivity, and $R_{\mathrm{sh}}$ is mud resistivity.

(2) In clean sandstone formation, the Archie formula (Archie, 1942) can be utilized.

$$
S_{\mathrm{w}}=\left(\frac{a \cdot b \cdot R_{\mathrm{w}}}{\phi^{m} \cdot R_{\mathrm{t}}}\right)^{1 / n}
$$

where $a$ is the lithological index, $m$ is the pore structure index, $n$ is the saturation index.

Currently, the LWD logs usually only have gamma and resistivity data. Therefore, we can only evaluate the shale quantitatively. The porosity and saturation parameters can only be estimated using a statistical model referencing to the wireline log evaluation results of nearby wells.

\subsubsection{Real-time visual interpretation of LWD data}

Because the reservoir property interpretation model and parameters are different for different regions, field engineers in different regions need to use different interpretation models. For this requirement, we designed and developed a generic reservoir property interpretation model, called a model generator, which can generate an appropriate local interpretation model by inputting and adjusting the model formula and parameters.

The interpretation model and specific parameters can be input using the reservoir property interpretation model generator, so that we can calculate the reservoir parameters in real-time using the real-time LWD data, and then display the interpretation results using the real-time display software module (Fig. 7).

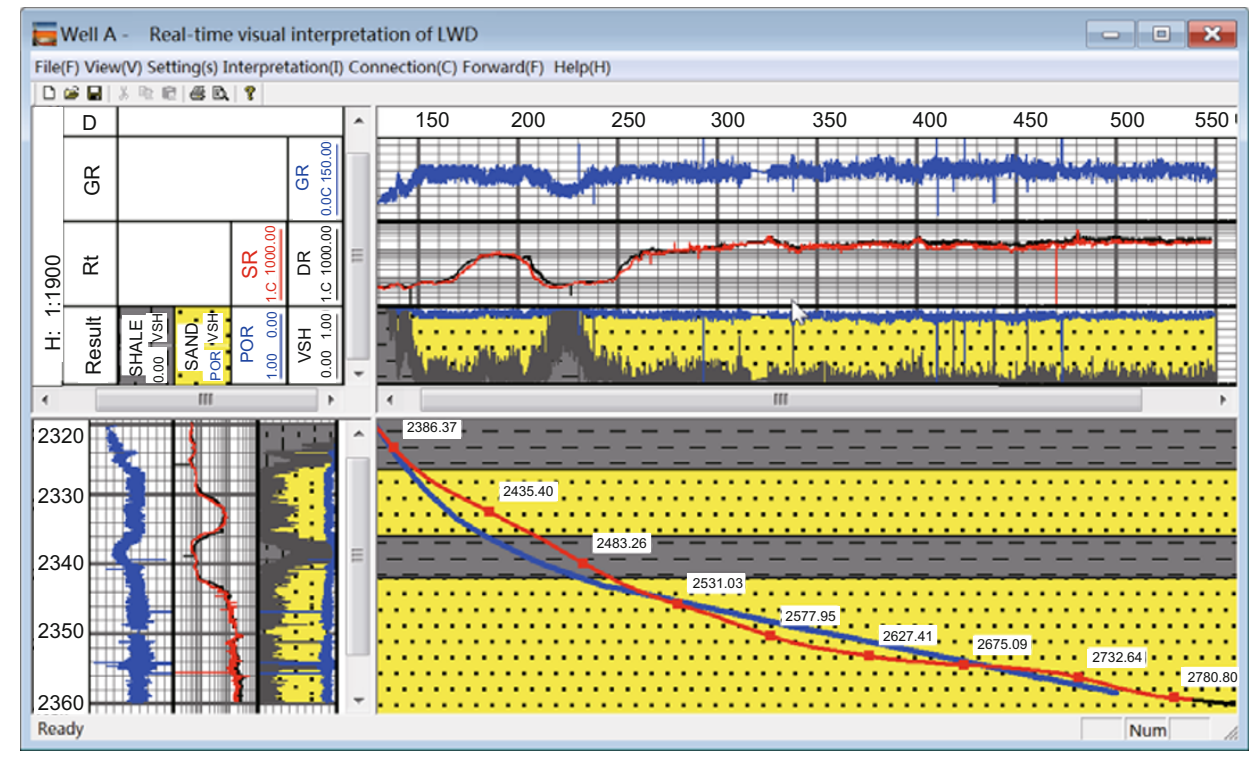

Fig. 7 Real-time visual interpretation of LWD data (D: displacement)

\subsection{Real-time updating of geological models and geo- steering}

Because of the uncertainty of the pilot geological model, the target of the designed well path is often inconsistent with the actual strata. Therefore, in order to realize geo-steering effectively, the configuration of strata and reservoir properties need to be updated in real time based on the interpretation of LWD data. Then the proposed well trajectory can be adjusted as a result of the updated information.

\subsubsection{Real-time updating method of formation structure}

The formation structure parameters include thickness, dip angle, azimuth, etc.

1) Using the spatial relationship between the geological model and wellbore information

With the help of $3 \mathrm{D}$ visualization and 2D projection decomposition techniques, we can observe and analyze the formation properties from different perspectives along the well trajectory, project the drilling path into the formation, determine the actual formation boundaries using LWD curves 
and update the strata model properly.

2) Using the intersections of the well trajectory and formation boundaries to estimate the formation thickness and dip angle

During the drilling of highly deviated and/or horizontal wells, S-shaped drilling paths tend to occur repeatedly in target strata because of the uncertainty of the initial strata model, an excessive decrease or increase of drill bit inclination, and the lack of near-bit information due to LWD position lagging the drill bit (Fig. 8) as the drill is further down the hole than the LWD sensors.

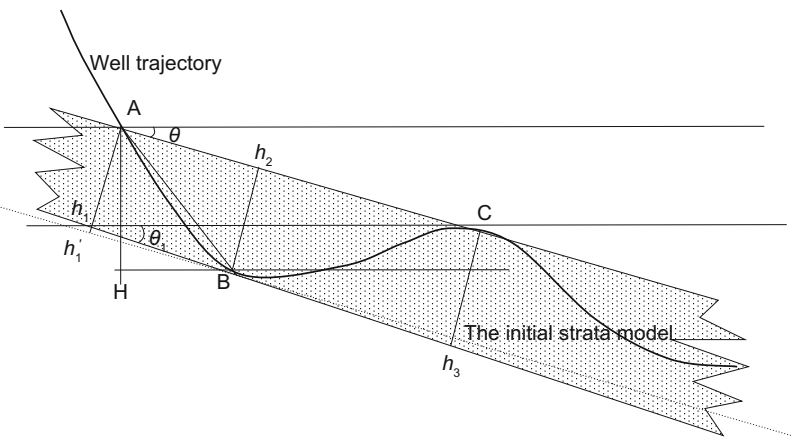

Fig. 8 Estimating formation thickness variation using well trajectory and LWD curves

The real-time interpretation of LWD data can help determine the contact positions of the well trajectory and formation boundaries (points A, B, C), which enable us to calculate formation thickness according to the well trajectory configuration within the formation boundaries, determine the variation of formation thickness and dip angle, and reduce the uncertainty of the formation structure model for drilling steering.

Through the two-dimensional projection displayed in horizontal and vertical planes (Fig. 6), we can visually determine the relation between the well trajectory and the formation boundaries. Then, by using the above method we can quickly estimate the thickness variation of the formation model.

3) Determining the formation dip angle using the azimuthal LWD data

Using the LWD azimuthal data, we can determine the intersection positions of the high side and low side of the borehole relative to formation boundaries and calculate the depth difference between the top and bottom intersection positions along the borehole axis. Combining this with the well deviation angle and borehole diameter, we can calculate the formation dip angle (Efnik et al, 1999). Fig. 9 shows the principle of determining dip angle using the azimuthal LWD data. Suppose that the well deviation angle is $I$, formation dip angle is $\alpha, \Delta D$ is the depth difference between the top and bottom intersections of the formation and the borehole, $D e$ is the borehole diameter.

Using the geometric relationship:

$$
\beta=90-I+\alpha=\tan ^{-1}(D e / \Delta D)
$$

We get the dip angle as:

$$
\alpha=\tan ^{-1}(D e / \Delta D)+I-90
$$

Using Eq. (7), we can provide a real-time estimation of the dip angle for the formation being drilled through.

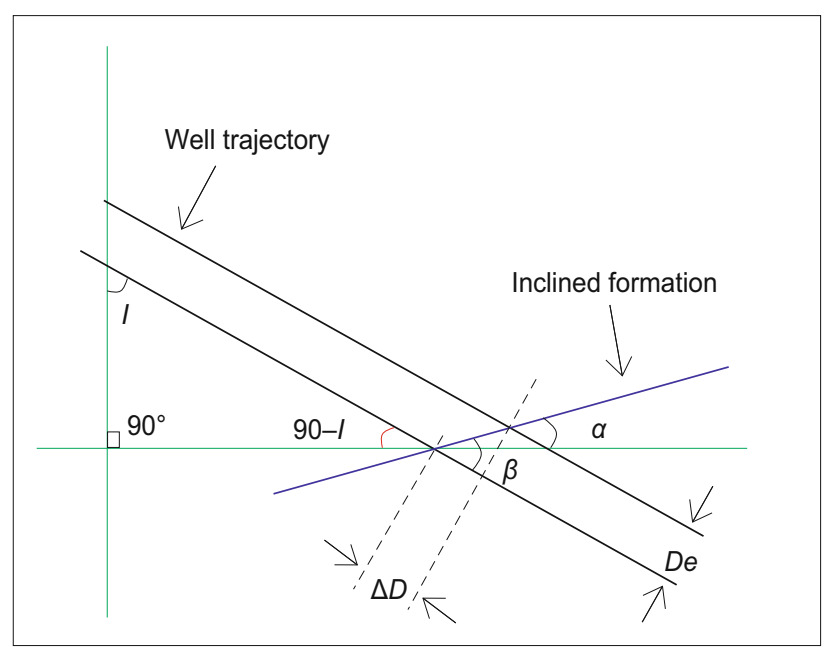

Fig. 9 Diagram illustrating the dip angle determination using the azimuthal LWD data

If the azimuthal LWD measurements are penetrating enough, such as deep azimuthal resistivity measurements (PeriScope of Schlumberger and ADR of Halliburton), the position of the formation boundary and dip angle can be estimated in real-time before the measurement point touches the boundary.

\subsubsection{The method for real-time updating reservoir property parameters}

In order to update the reservoir property parameters, it is necessary to determine the formation lithology, physical properties, and fluid type in real time. Since the gammaray and resistivity log data are usually available from LWD measurements, the following methods can be utilized to estimate these reservoir properties.

\section{1) Lithology determination}

The lithology variation of the drilled formation can be determined by the LWD gamma-ray data, according to features of gamma-ray curve in the sand-shale formation.

In addition, the lithology variation can also be determined by the stratigraphic correlation of log curve characteristics of the marker beds in nearby wells. According to the $2 \mathrm{D}$ or $3 \mathrm{D}$ visualization of the stratigraphic correlation, and the log curve characteristics of LWD and the marker beds, we not only can estimate the lithology of the current formation being drilled, but also can judge whether the target layer has been reached. Fig. 10 displays the contrast diagram of one work area. The characteristics of the real-time LWD data (Well B) are similar to those of the adjacent well near the top of the reservoir interval, which signifies that the target layer has been reached. 2) Determination of reservoir physical properties and fluid type

According to the above LWD data interpretation method, 


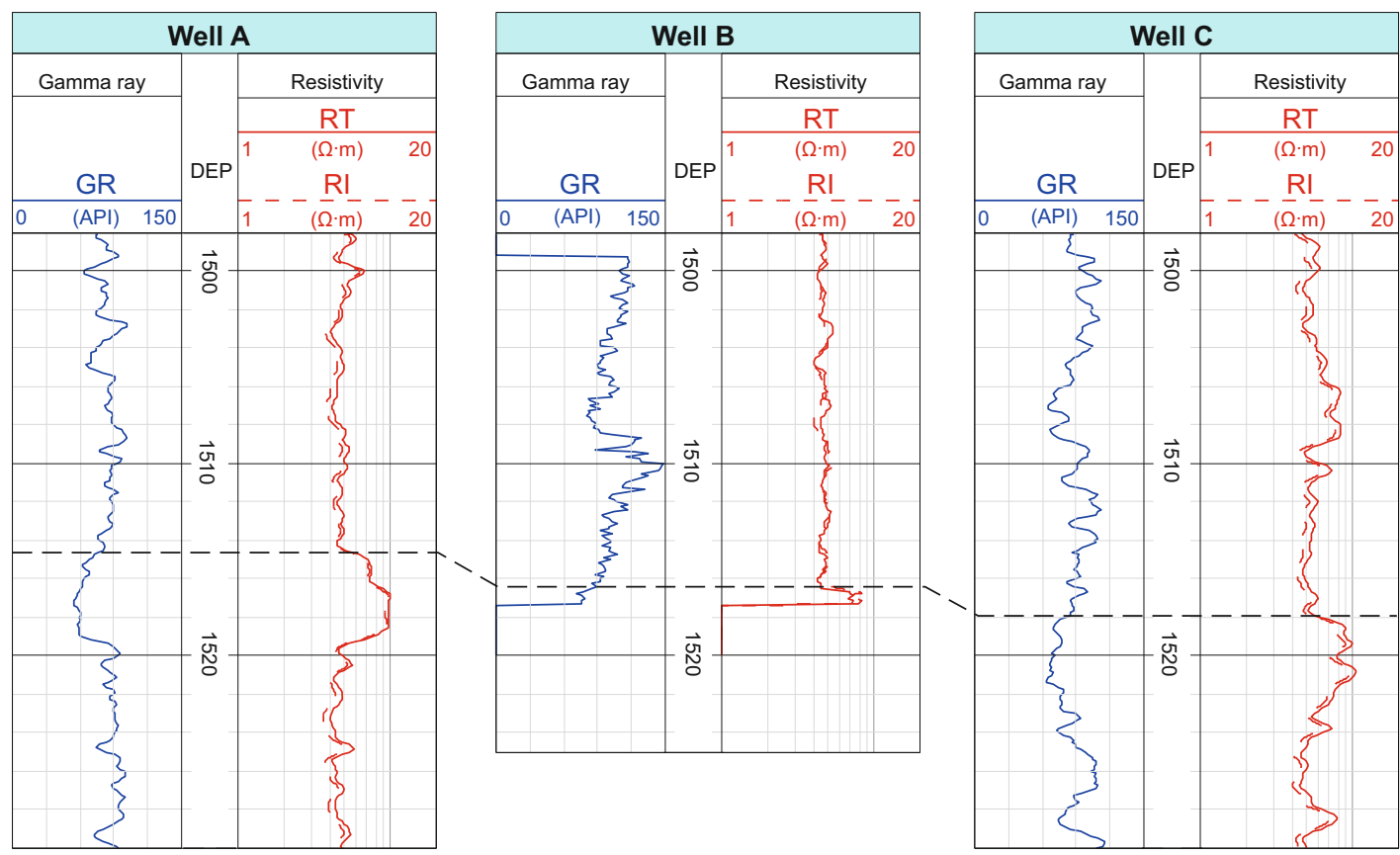

Fig. 10 Using stratigraphic correlation to determine the target layer

we can estimate the shale volume, porosity, saturation, and permeability quantitatively in real time, yielding the formation parameters along the well trajectory. Then using these parameters as hard constraints and utilizing a proper modeling method, we can update the properties of the geological model quickly at the well site.

\subsubsection{Real-time updating of the geological model and geo-} steering

During the drilling process, we can update the geological model in real time using the LWD data processing and interpretation results and the structure and property determination method mentioned above. The geological model updating flow chart is illustrated in Fig. 11.
Based on the real-time interpretation of LWD data and geological model updating, together with the $3 \mathrm{D}$ visualization of the wellbore geological information and geological model, we can visually analyze the difference between the actual formation model and the prior model. The procedure allows us to adjust the well path in a timely manner and ultimately realize drilling geo-steering in $3 \mathrm{D}$ space.

\subsubsection{Example}

Fig. 12 displays the geo-steering example of a well in western China. The solid red line on the GR track in the top window is the forward modeled gamma-ray response curve, and the blue one is the measured gamma-ray curve. The lower right side window shows the actual formation model (the
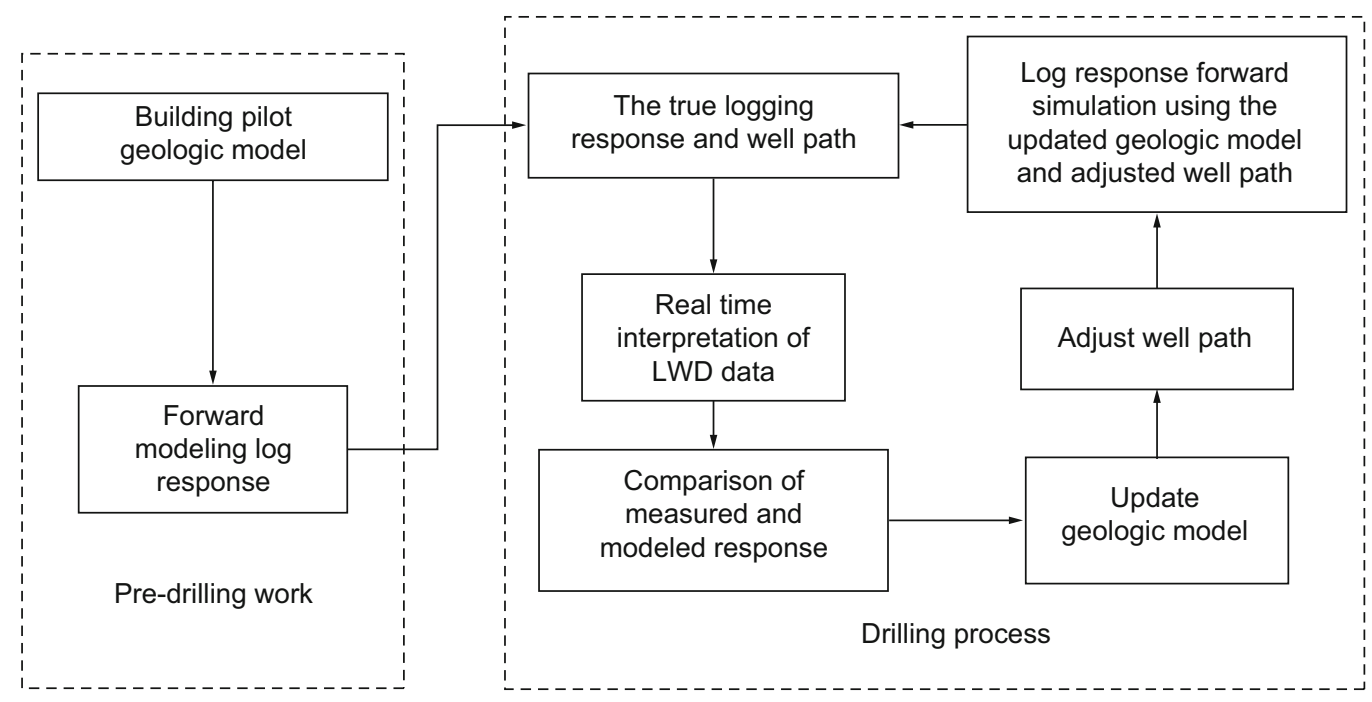

Fig. 11 The real-time flow chart for geological model updating based on the LWD data interpretation 
yellow-shaded background is sandstone, and the gray-shading is mudstone) and the borehole trajectories (the blue one is the designed trajectory, and the red one is the drilled trajectory). It can be seen from the figure that the target landing point is at 1,624 $\mathrm{m}$ depth. From then on, the drilled wellbore trajectory is kept steadily in the target layer by building and holding the inclination angle of the drill bit. Real-time interpretation results of the reservoir parameters show that the gamma-ray log value (shale content) increases over the horizontal distance 284-304 m. Combining modeled and measured gamma-ray response curves we can judge that the top boundary has been encountered. Afterwards, the drilling is steered to reduce the well deviation angle to drill back into the reservoir. Real-time LWD interpretation results show that the shale content increases again in the horizontal distance interval 350-366 m. Again, by comparing the modeled and measured gamma-ray response results, we can judge that the well trajectory has touched the bottom boundary of the reservoir. The drilling is then adjusted by gradually increasing the well deviation angle to re-enter the target layer.

Using the above method for real-time LWD data interpretation and geological model updating, we estimate that the thinnest reservoir stratum confining the well trajectory is about $1 \mathrm{~m}$. Moreover, with real-time LWD data interpretation and geological model updating, the well path can be accurately adjusted. The procedure results in a landing depth at 1,624 m, which is $36 \mathrm{~m}$ ahead of the designed depth. The vertical depth of the oil formation top is $2.4 \mathrm{~m}$ higher than the originally estimated depth. The borehole horizontal length in formation is $35 \mathrm{~m}$ longer than the pre-designed length. The final well trajectory has a success rate of $91.5 \%$ within the oil formation.

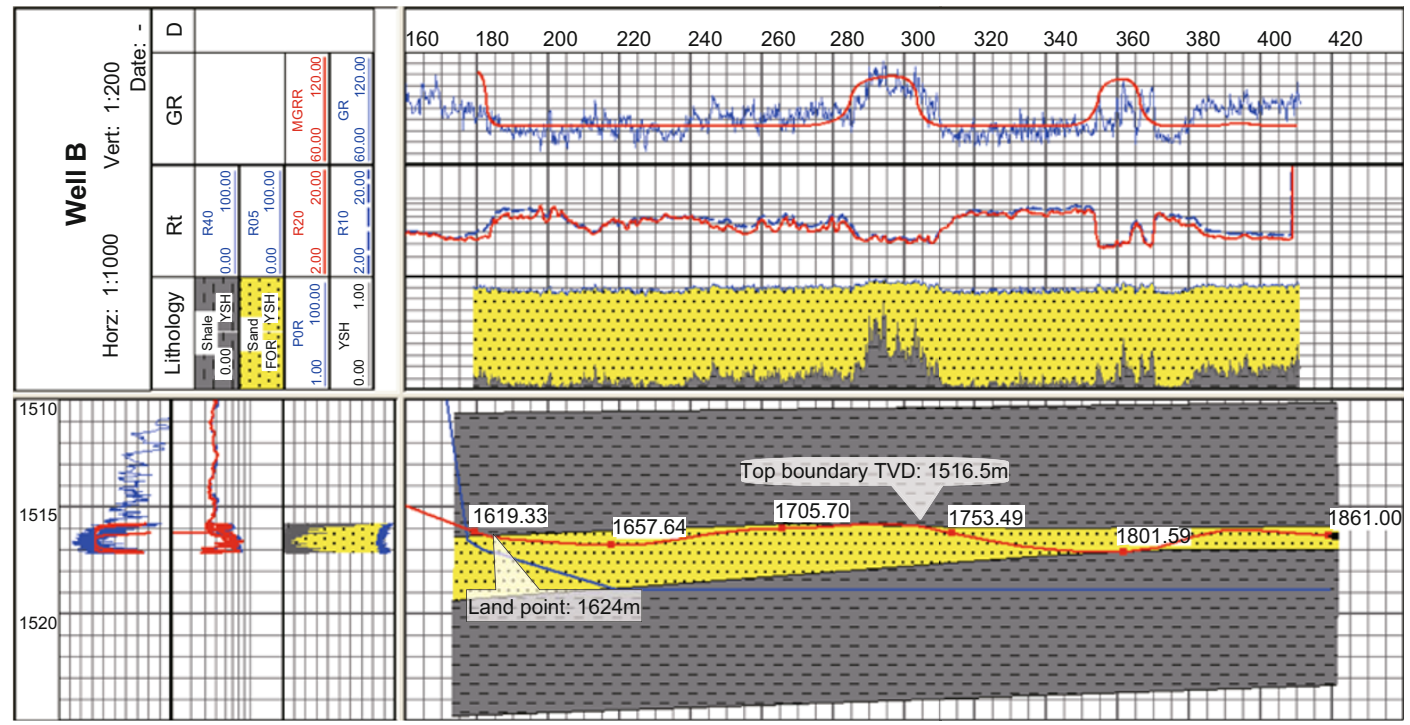

Fig. 12 An application example for a well in western China (D: displacement)

\section{Conclusion}

Using real-time interpretation of LWD data and geological model and borehole information visualization, combining with the integrated application of computer communications and $3 \mathrm{D}$ visualization technology, we developed a software application for three-dimensional visualization drilling geo-steering, providing a useful geo-steering technology with Chinese intellectual property rights. The software has been applied in a number of domestic oil fields, with good results, enabling domestic drilling industries to become more competitive and enabling oil companies to reduce cost in drilling their wells. Some shortcomings and problems are also found in the application, which need further research and development.

\section{Acknowledgements}

The research work is funded by several Co. of CNPC and SINOPEC, and China National Science and Technology
Major Projects of Oil \& Gas (2011ZX05009-003), and "863" Projects (2006AA060105). In addition, we thank Professor Tang Xiaoming for the thoroughgoing revision of the paper.

\section{References}

Archie G E. The electrical resistivity log as an aid in determining some reservoir characteristics. Transactions of the AIME. 1942. 146(1): 54-62

Balan B, Mohaghegh S and Ameri S. State-of-the-art in permeability determination from well log data: Part 1-A comparative study, model development. SPE Formation Evaluation. 1997. 12(3): 170174 (SPE 30978)

Barillot C. Surface and volume rendering techniques to display 3-D data. IEEE Engineering in Medicine and Biology Magazine. 1993. 12(1): 111-119

Bazara M, Maalouf J, Al-Sharafi M, et al. Logging while drilling resistivity images for geosteering. 18th Middle East Oil \& Gas Show and Conference (MEOS), 10-13 Mar 2013. Bahrain International Exhibition Centre, Manama, Bahrain (SPE 164220-MS)

Efnik M S, Hamawi M, Al-Shamri A, et al. Using new advances in LWD 
technology for geosteering and geologic modeling. Middle East Drilling Technology Conference, 8-10 November 1999. Abu Dhabi, United Arab Emirates (SPE/IADC 57537)

Fertl W H and Hammack G W. A comparative look at water saturation computations in shaly pay sands. The Log Analyst. 1972. 13(2): 1220

Heaton N, Jain V, Boling B, et al. New generation magnetic resonance while drilling. SPE Annual Technical Conference and Exhibition, 8-10 October 2012. San Antonio, Texas, USA (SPE 160022-MS)

Jones A and Ohlund J. Network Programming for Microsoft Windows. Washington: Microsoft Press. 2002

Levoy M. Display of surfaces from volume data. IEEE Computer Graphics and Applications. 1988. 8(3): 29-37

Liu S, Lucas J L, Plemons P A, et al. Challenges to geosteering and completion optimization of horizontal wells in the Cotton Valley Formation, East Texas. 2013 SPE Middle East Unconventional Gas Conference \& Exhibition, 28-30 Jan 2013. Muscat, Sultanate of Oman (SPE 163979-MS)

Li Y, Xue H B, Zhu B L, et al. OpenGL Function with Example Parse Manual. Beijing: National Defence Industry Press. 2002. 1 (in Chinese)

Lorensen W E and Cline H E. Marching cubes: A high resolution 3D surface construction algorithm. ACM Siggraph Computer Graphics. 1987. 21(4): 163-169

Mickael M, Phelps D and Jones D. Design, calibration, characterization, and field experience of new high-temperature, azimuthal, and spectral gamma ray logging-while-drilling tools. SPE Annual Technical Conference and Exhibition, 29 September - 2 October, 2002. San Antonio, Texas (SPE 77481-MS)

Pears N, Liu Y H and Bunting P. 3D Imaging, Analysis and Applications. London: Springer-Verlag. 2012

Peeters M. Review of shaly sand evaluation models and introduction of a new method based on dry clay parameters. SPWLA 52nd Annual Logging Symposium held in Colorado Springs, Co, USA. 14-18 May 2011 (SPWLA 2011 BB)

Rosthal R A, Young R A, Lovell J R, et al. Formation evaluation and geological interpretation from the resistivity-at-the-bit tool. SPE Annual Technical Conference and Exhibition, 22-25 October 1995. Dallas, Texas (SPE 30550-MS)
Saikia K. Real-time modeling-while-drilling for optimized geosteering and enhanced horizontal well placement in thin and complex reservoirs. 6th International Petroleum Technology Conference, 2628 Mar 2013. Beijing, China (IPTC 16715)

Sawaryn S J and Thorogood J L. A compendium of directional calculations based on the minimum curvature method. SPE Drilling \& Completion. 2005. 20(1): 24-36 (SPE 84246-PA)

Schlumberger Wireline \& Testing. Log Interpretation Principles/ Applications. Sugar Land, Texas. March 1998

Shao C R, Tang H Q and Zhang F M. Current situation and research trend of the evaluation technique for LWD interpretation. Petroleum Geology \& Oilfield Development in Daqing. 2010. 29(5): 158-163 (in Chinese)

Simandoux P. Dielectric measurements in porous media and application to shaly formations. Revue de. L'Institut Français du Pétrole. 1963. Suppl. Issue: 193-215

Swire P, Badr Y, Ramadan Z J, et al. Steering with the multifunction LWD tool achieves optimum results in high structural uncertainty field in Egypt. 18th Middle East Oil \& Gas Show and Conference (MEOS), 10-13 Mar 2013. Bahrain International Exhibition Centre, Manama, Bahrain (SPE 164282-MS)

Tang X M, Patterson D and Wu L. Measurement of formation permeability using Stoneley waves from an LWD acoustic tool. Petrophysics. 2010. 51(2): 66-74

Timur A. An investigation of permeability, porosity, and residual water saturation relationship for sandstone reservoirs. The Log Analyst. 1968. 9(4): 8

Wang H, Ye A L and Cao L Y. Visual C++6.0 Program and Skill. Beijing: China Machinery Industry Press. 1999. 11 (in Chinese)

Wheeler A J, Billings T, Rennie A, et al. The introduction of an at-bit natural gamma ray imaging tool reduces risk associated with realtime geosteering decisions in coalbed methane horizontal wells. SPWLA 53rd Annual Logging Symposium, 16-20 June 2012. Cartagena, Colombia (SPWLA 2012-167)

Yong S H and Zhang C M. Logging Data Processing and Comprehensive Interpretation. Dongying: China University of Petroleum Press. 1996. 9 (in Chinese)

(Edited by Hao Jie) 